\title{
Gold geochemical anomaly and pros- pecting prediction in the southern section of Jiaojia fault zone, Jiaodong gold province, eastern China
}

\author{
M.J. XI*, K.Q. ZHAO AND S.M. MA
}

Institude of Geophysical and Geochemical Exploration, CAGS, CGS, Langfang 065000, China (*correspondence: mingjiexi@163.com)

Jiaodong gold province is an most important gold concentration of China. Jiaojia gold belt was situated in the western part of the Jiaodong peninsula and controlled by the Jiaojia fault zone, many extra-large and large gold deposits were discovered in this belt, such as the Jiaojia, Xincheng, Hexi and Sizhuang gold deposits. The location, morphology and metallogenic potential of the northern section of the Jiaojia fault zone has been well constrained. However, the metallogenic geological conditions and metallogenic potential of the southern section of the Jiaojia fault zone was found hard to determine, since the southern section was covered gradually by the quaternary sediments from the south of Ziluojijia, which has restricted the prospecting progress of the Jiaodong gold deposit.

Soil geochemical study was carried out within the range of $400 \mathrm{~km}^{2}$ in the Shahe area in the southern section of Jiaojia fault zone. The soil samples were sampled from $30-50 \mathrm{~cm}$ below the surface of earth, and the sampling grain size was -200 mesh. The contents of Au and Hg in 2481 samples were analyzed by inductively coupled plasma mass spectrometry and atomic fluorescence spectrometry.

The results showed that the elements of $\mathrm{Au}$ and $\mathrm{Hg}$ were enriched in the soil of the study area, four geochemical anomalies for each of $\mathrm{Au}$ and $\mathrm{Hg}$ were identified in Dongsong, Nashilibo, Dongshen and Xiaqiu regions. Dongsong $\mathrm{Au}$ anomaly distributed along the Liucun fault zone, which was consisting with the known Liucun quartz vein type gold deposit. A significant $\mathrm{Hg}$ anomaly was discovered in the soil samples above the gold orebody, and the combined anomalies of $\mathrm{Au}$ and $\mathrm{Hg}$ could be used as geochemical indicators for prospecting concealed gold mineralization in this area. Two ore-prospecting prediction areas were delineated in Dongshen and Xiaqiu region by the comprehensive anomalies of $\mathrm{Au}$ and $\mathrm{Hg}$, both of which occurred at the intersection of northeast and northwest faults. Besides, the ratio of $\mathrm{Au} / \mathrm{Hg}>7.0$ was used to delineate the anomalies in Shahe area, was conducive to eliminating the interference caused by human activities to $\mathrm{Au}$ anomalies, quickly narrowing down the range of $\mathrm{Au}$ anomalies, and further clarifying the prospecting direction. 